\title{
AVALIAÇÃO DO PODER SELETIVO DO MEIO DE RAPPAPORT PARA DIVERSAS ESPÉCIES DE ENTEROBACTÉRIAS ( $\left.{ }^{*}\right)$
}

\author{
Deise P. Falcão **, Italo Suassuna e lrone R. Suassuna ***
}

Foi feita uma avaliacão dos mecanismos de seletividade e inibição do meio de Rappaport em relação a espécies representativas do enterobactérias. o meio hipertônico original, com $3,6 \%$ de cloreto de magnésio demonstrou-se inib,dor para Salmonella typhımurium, a qual foi ainda inibida à concentração de3,1\%. Não se verificou crescinento de todas as espécies de shigella, a partir da concentração de $1.8 \%$, Escherichia coli a partir de 2,2\%, Enterobacter a partir de $3,1 \%$ e Proteus mirabilis so com $3,6 \%$.

o verde malaquita na concentração original de $0,012 \%$ demonstra capacidade de inibição do crescimento de tôdas as espécies testadas, com a exceção de Enterobacter $e \mathrm{~s}$. typhimurium.

A substituição do fosfato diácido de potássio pelo correspondente sal de sólio, atenua o poder inibidor do meio para tôdas as espécies bacterianas estudadas.

As shigelas revelaram-se as enterobactérias mais sensiveis em relacão $a$ Êsse meio, sendo igualmente inibidas pelos meios à base do tiosulfado dé cá!cio ou de magnésio, também inspirados no emprêgo de soluções hipertônicas.

Ao serem introduzidas as técnicas de preservação e transporte de fezes por dessecação em fôlhas de papel de filtro, foi feita a verificação de que os germes de mencr significação como patogênicos intestinais, tais como Proteus e Escherichia, seriam mais sensiveis à dessecação que os germes patogênicos.

Fundamentando-se nessa apreciação, $\epsilon$ em que o efeito da dessecação equivalia ao de uma alta pressão osmótica, Rappaport e colabcradores $(11,12,13)$ em sucessivas comunicações desereveram alguns mieios baseados no princípio da hipertonicidade, para o crescimento seletivo de Salmonella, com o emprêgo de soluçốes de tiosulfato de cálcio ou de magnésio (13) ou ainda de cloreto de magnésic $(11,12)$ asscciando outros mecanismos de inibiçāo dos demais componentes da microbiota intestinal, como um baixo pH (13) cu a adição de corantes $(11,12)$.

O meio da Rappaport com cloreto de magnésio e verde malaquita tornou-se mais conhecido, e foi submetido à avaliação por alguns autores, destacando-se Collard \& Unwin (3), Hooper \& Jenkins (6), Iveson e colaboradores $(8,9)$ e Anderson \& Kennedy (1) que confirmaram a sua eficácia para Salmoneilla. Banic (2) alterou a composição do meio, por achar excessiva a concentração original do sal de magnésio, para o crescimento seletivo dêsses germes, e Zajc-Satler \& Banic (15) e Raj (10) acharam-no inferior a outros meics conhecidos.

Um pequeno número de amostras de Shigellu sonnei foi isolado por Hooper \& Jenkins (7) com o meic de Rappaport, e o fato atraiu a nossa atenção $\mathrm{\epsilon m}$ face da avarente insuficiência dos processos dis.. noniveis para o isclamento de Shigella $(3,5)$. Propusemo-ncs, assim, a averiguar a eficácia dos mecanismos de inibição do meio, $\mathrm{ccm}$ o proposito de confirmar ou adaptar o seu emprêgo, ao isolamento de

(*) Trabalho do Departamento de Microbiologia Médica do Instituto de Microbiologia da U.F.R.J., Guanabara. Com auxilio do Conselho Nacio nal de Pesquisas e do Conselho de Pesquisas da U.F.R.J.

(“) Enderếro atual: Faculdade de Farmácia e Odontologia de Araraquara, São Paulo, Bolsista da CAPES.

(**) Chefe de Pesquisas do Conse'ho Nacional de Pesquisas. 
outros germes patogênicos intestinais, especialmente Shigella. Resultados preliminares dêsse estudo foram anteriormente divulgados (6).

\section{MATERIAL E MÉTODOS}

O meio de Rappaport, Konforti \& Navon (12), com cloreto de magnésio, em sua fórmula original corresponde a:

\section{A - Bacto-Tryptone $\mathrm{NaCl}$ $\mathrm{KH}_{2} \mathrm{PO}_{4}$ Água bidestilada}

B - Juntar $10 \mathrm{ml}$ de solução de cloreto de magnésio a $40 \%$

C - Acrescentar $3 \mathrm{ml}$ ce solução de verde de malaquita a $0,4 \%$.

Em relação a essa fórmula básica foram feitas modificaçóes, estudando-se a - substituição do fosfato diácido de potássio pelo fosfato de sódio correspondente; substituição da solução de cloreto de magnésio, por outras menos concentradas, isto é, a $20,25,30$ e 35 por cento, adicionadas ao meio na mesma proporção $(10 \mathrm{ml}$ para cada $100 \mathrm{ml}$ de meio), resultando em concentrações finais de $1,8 \%, 2,2 \%, 2,7 \%$, $3,1 \%$ e, finalmente, omitindo 0 emprêgo do corante, conforme apresentamos adiante.

Outros meios, descritos por Rappaport, Skariton-Loewenthal \& Olitzki (13) obedeceram à seguinte formulação:

\section{A - Bacto-Peptona $\mathrm{NaCl}$ \\ $\mathrm{NaH}_{2} \mathrm{PO}_{4}$ Água destilada}

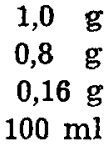

O fosfato de sódio foi usado em lugar do fosfato monopotássico em face a verificações que serão detalhadas a seguir. Para cada $5 \mathrm{ml}$ dêsse meío, foram adicionados volumes variáveis de solução de tiosulfato de cálcio ou de tiosulfato de magnésio, preparadas de acôrço com as fórmulas abaixo:

$$
\begin{aligned}
\mathrm{B}- & \mathrm{Na}_{2} \mathrm{~S}_{2} \mathrm{O}_{3} \\
& \mathrm{CaCl}{ }_{2} \\
& \text { Agua destilada } \\
\mathrm{C}- & \mathrm{Na}_{2} \mathrm{~S}_{2} \mathrm{O}_{3} \\
& \mathrm{MgCl}_{2} \\
& \text { Agua destilada }
\end{aligned}
$$

Foram utilizadas nas experiências nove estirpes bacterianas da Coleção do Laboratório de Enterobactérias, as quais corresponderam às seguintes espécies: Shigella dysenteriae, Shigella flexneri, Shigella boydii, Shigella sonnei, Salmonella typhi, Salmonella typhimurium, Proteus mirabilis, Escherichia coli e Enterobacter sp.

$\mathrm{Na}$ execução de experiências sôbre 0 rendimento ou poder inibidor das diferentes formulaçōes do meio, eram feitas diluições sucessivas em solução salina isotônica, na razáo de ordem 10 (de 10-1 a 10-8) a partir de cultivo de 20-24 horas em caldo simples. De cada diluição eram imediatamente retiradas alíquotas de 0,1 $\mathrm{ml}$, as quais serviam de inóculo para $5 \mathrm{ml}$ Ce cada meio. Uma aliquota era simultâneamente distribuída em $5 \mathrm{ml}$ de solução salina e, de modo imediato, após homogeneizlação, retirava-se $0,1 \mathrm{ml}$ para semeadura em meio de Holt-Harris \& Teague e posterior contagem do número de colônias correspondente ao inóculo empregado. De modo semelhante, $0,1 \mathrm{ml}$ de cada um dos meios que recebiam o inóculo proveniente das diversas diluiçōes, após 24 horas de incubação a $37^{\circ} \mathrm{C}$ em estufa bacteriológica, era semeado no mesmo meio de Holt-Harris \& Teague, com a finalidade de enumerar as colônias e avaliar o efeito das modificações introduzidas no meio de Ran. paport. O processo é esquematizado na seqüência a seguir:
$0,1 \mathrm{ml} \mathrm{em}$ $5 \mathrm{ml}$ de salina

Imediato

$0,1 \mathrm{ml}$<smiles>[Y][Te]</smiles>

Holt-Harris \& Teague

$$
18 \mathrm{~g}
$$

$100 \mathrm{ml}$

$16 \mathrm{~g}$

$18 \mathrm{~g}$ $100 \mathrm{ml}$

\section{Diluições $(10-1$ a 10-8)}

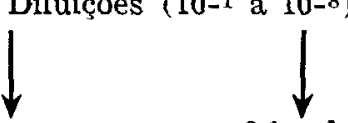

$0,1 \mathrm{ml} \mathrm{em}$

$5 \mathrm{ml}$ de salina<smiles>C[Te]</smiles>

Incubação $\left(37^{\circ} \mathrm{C}\right.$

- $24 \mathrm{hs}$ )

$0,1 \mathrm{ml}$

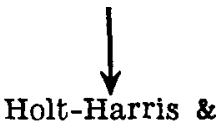
Teague

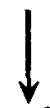

Incubação $\left(37^{\circ} \mathrm{C}\right.$

- 24 hs) Contagem de colônias
Incubação $\left(37^{\circ} \mathrm{C}\right.$

- 24 hs) Contagem de colônias 
Tôdas as contagens foram realizadas em duplicatas, fazendo-se a média dos valôres obtidcs entre 30 a 300 colônias por placa.

\section{RESULTADOS}

Inicialmente procuramos avaliar a eficácia de concentrações menores de cloreto magnésio no meio da Rappaport sôbre o crescimento de diférentes enterobactérias, pelo que omitimos a inclusão do verde malaquita. Soluções a 20, 25, 30 e 35 por cento foram preparadas e adicionadas ao meio básico, na mesma proporção $(10 \mathrm{ml}$ para cada $100 \mathrm{ml}$ do meio) em que entrava a solução a 40 por cento. Em uma ocasião, durante ensaios preliminares com o meio de Rappaport, o fosfato diácido de sódio, foi utilizado por equívoco ao invés do sal correspondente de potássic, observando-se uma atenuação do poder inibitório do meio para as espécies de shigella, além de outras, conforme pode apreciar-se nos resultados reproduzidos no Quadro I. O quadro mostra comparativamente a influência dos fosfatos de sódio e de potássio, em presença de 3,6 por cento de cloreto de magnésio, o que corresponde à concentração original do meio de Rappaport.

O Quadro II apresenta os resultados da comparação de ambos os fosfatos combinados a concentrações decrescentes de cloreto de magnésio. Observa-se que o efeito lesivo sôbre o crescimento de Shigella está sempre presente a partir da concentração mínima de $1,8 \%$ de cloreto de magnésio, embora mais atenuado com o fosfato de sódio. Em relação a $S$. typhi o efeito inibidor surge a partir de $2,7 \%$ e a partir de $3,1 \%$ para $S$. typhimurium A supressão do crescimento de $E$. coli e Enterobacter é aparente, a partir de $2,7 \%$ para $E$. coli, e não se observa até $3,1 \mathrm{em}$ Enterobacter. $P$. mirabilis só foi inibido com a concentração original de $3,6 \%$ de cloreto de magnésio (Quadro I). Considerando-se os Quadros I e II, seja observado que pràticamente com tôdas as estirpes, e em tôdas as dez variações do meio básico, houve diminuição do efeito inibidor quando utilizado o fosfato de sódio, em substituição ao fosfato de potássio.

Em face a êsses primeiros resuitados, adotou-se o fosfato diácido de sódio, na mesma concentração do de potássio $\mathbf{e}, \mathbf{\epsilon m -}$ pregando $1,8 \%$ do cloreto de magnésio, estudamcs o efeito da incorporação do verde malaquita sôbre as diferentes espécie; bacterianas estudadas.

Os $_{\text {S }}$ resultados condensados no Quadro III revelam, em ausência do verde malaquita, estímulo no crescimento de quase tôdas as estirpes consideradas, ircluindo mesmo Sh. dysenteriae e Sh. sonnei, com o que desapareceram, nessas condições, as caracteristicas seletivas do meio, que apenas conservou o poder inibidor sôbre as duas outras espécies de shigella, i. e., $S h$. flexneri e Sh. boydii. Com a introdução do verde malaquita (Quadro IV), comprova-se inibição de quase tôdas as espécies, discreta embora quanto a $S$. typhi e $P$. mirabilis, excetuando-se a êsse respeito apenas $s$. typhimurium e Enterobacter, que não sofreram inib̄ição.

Em um último ensaio, foram comparados os outros meios descritos por Rappaport e colaboradores (13), à base de tiosulfato de magnésio e tiosulfato de cálcio, para verificação de seu poder inibidor sôbre as quatro espécies de Shigella. O Quadro V resume essas verificações, comprovando igualmente a grande sensibilidade de Shigella às soluções hipertônicas empregadas.

\section{DISCUSSÃO}

Diante da experimentação parece cyìdente não haver condições que permitam o emprêgo do meio de Rappaport para a seleção de enterobactérias patcgẻnicas outras, além de Salmonella. A Sh. dysenteriae e a $S h$. sonnei, embora mencs sensiveis que as outras shigelas, só crescem bem nas soluções hipertônicas do cloreto de magnésio em concentrações nas quais perde-se, pràticamente, tôda a seletividade do meio.

Os achados em relação a $S$. typhi, isto é, inibição a partir de $2,7 \%$ de cloreto de magnésio, coincidem com os dados de Rappaport $(11,12)$ que, originalmente, recomenda o meio para o isolamento de Salmonella, excluindo a $S$. typhi. A inadequaçāo do meio para essa última espécie é ainda comprovada pelas verificações de Anderson \& Kennedy (1) e Iveson \& Kovacs (8), que o aplicaram ao estudo de número considerável de espécimens de fezes.

Em relação a Salmonella, dado o caráter necessàriamente limitado de nossas ob- 


\section{QUADRO I}

Ação inibitória do cloreto de magnésio na concentração de $3,6 \%$, em presença de fosfato ácido de sódio, ou fosfato acido de potásisio, no meı

Espécie

Inóculo

Contagem de colônias em $0,1 \mathrm{ml}$ após (Contagem de cclônias em
$0,1 \mathrm{ml}$ )
Com $\mathrm{KH}_{2} \mathrm{PO}_{4}$
Com $\mathrm{NaH}_{2} \mathrm{PO}_{4}$

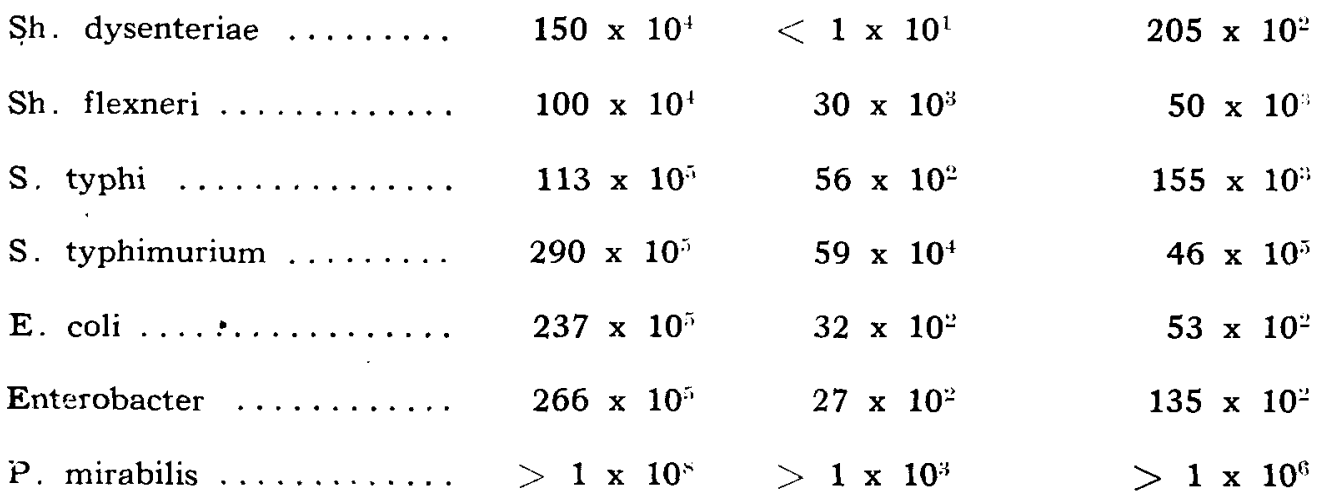

QUADRO III

Efeito do meio de Rappaport modificado (*) sem adição de verde malaquita, sôbre diversas enterobactérias

Espécie Inóculo $(\mathrm{em} 0,1 \mathrm{ml}) \quad \begin{gathered}\text { N. } \\ \mathrm{ml} \text { de células em } 0,1 \\ \text { após } 24 \text { horas }\end{gathered}$

Shigella dysenteriae

Shigella flexneri

Shigella boydii

Shigella scnnei

Salmonella typhi

Salmonella typhimurium

Escherichia coli

Proteus mirabilis

Enterobacter sp.

$62 \times 10^{4}$
$63 \times 10^{4}$
$175 \times 10^{3}$
$93 \times 10^{4}$
$56 \times 10^{4}$
$98 \times 10^{4}$
$150 \times 10^{4}$
$>1 \times 10^{6}$
$105 \times 10^{4}$

$>1 \times 10^{7}$

$27 \times 10^{: 2}$

$85 \times 10^{2}$

$>1 \times 10^{\mathrm{s}}$

$300 \times 10^{5}$

$>1 \times 10^{7}$

$>1 \times 10^{8}$

$>1 \times 10^{8}$

$>1 \times 10^{7}$

(*) Com $1,8 \%$ de $\mathbf{M g C l}_{2}$ e $0,16 \%$ de $\mathrm{NaH}_{2} \mathrm{PO}_{4}$ 
Eieito de diferentes concentraçóes de ciorcto de ragneso em prosença KH-PO+ ou NaH-PO (a $0,16 \%$ )

Contagen de colonies em $0,1 \mathrm{ml}$ de meio após 24 horas a $37^{\circ} \mathrm{C}$

\begin{tabular}{|c|c|c|c|c|c|c|c|c|c|}
\hline \multirow[t]{2}{*}{ Espécie } & \multirow{2}{*}{$\begin{array}{l}\text { Inócula } \\
(\mathrm{em} 0,1 \\
\mathrm{ml})\end{array}$} & $1,0 \%$ de & $\mathrm{MgCi}$ & $2,2 \%$ de & $\mathrm{MSCl}$ & $27, \% \mathrm{de}$ & $\omega_{8}-$ & $3,1 \%$ de & \multirow{2}{*}{$\frac{\mathrm{MgCl}^{-}}{\mathrm{Na}^{+}}$} \\
\hline & & $\mathbf{K}^{+}$ & $\mathrm{Na}$ & $\mathbf{K}$ & $\mathrm{Na}^{+}$ & $\mathbf{K}+$ & Na:- & $\mathbf{K}^{+}$ & \\
\hline Shigela dysenteriae ... & $155 \times 10^{4}$ & $43 \times 10^{\prime}$ & $67 \times 10^{1}$ & $>300 \times 10$ & $86 \times-9$ & $250 \times 55^{1}$ & $57 \times 10$ & $40 \times 10^{2}$ & $52 \times 10^{2}$ \\
\hline Shigeila fleyneri . . . . . . & $200 \times 10^{4}$ & $61 \times 10^{2}$ & $160 \times 10$ & $50: 10^{t}$ & $50 \times 10$ & $150 \times 10^{*}$ & $52010:$ & $50 \times 10^{2}$ & $230 \times 10^{2}$ \\
\hline Singella boydii $\ldots \ldots \ldots \ldots$ & $119 \times 10^{4}$ & $220 \times 10^{4}$ & $35 \times 10^{-}$ & $50 \times 10^{\circ}$ & $58 \times 50^{:}$ & $54: 10$ & $37: 10^{4}$ & $30 \times 10^{4}$ & $53 \times 10^{4}$ \\
\hline Shigella sonnei & $180 \times 10^{4}$ & - & $50 \times 30^{4}$ & $57 \times 10^{\prime \prime}$ & $30 \times 10=$ & $14 \times 10^{1}$ & $46.10:$ & $14 \times 10^{1}$ & $30 \times 10^{1}$ \\
\hline Salmoneila typhi & $57 \times 10^{5}$ & - & $80 \times 10^{\circ}$ & $190 \times 10^{\circ}$ & $56 \times 10:$ & $200 \times 10^{\prime}$ & $202 \times 10^{\prime 3}$ & $33 \times 10^{2}$ & $56 \times 10^{+}$ \\
\hline Saim. typhimurium & $210 \times 10^{4}$ & $>1 \times 10^{.8}$ & $>1 x \pm 0$ & $>1 \times 10^{\circ}$ & $>1 \times 0^{\circ}$ & $>1 \times 10^{\circ}$ & $80 \times: 0:$ & $29 \times 10^{1}$ & $52 \times 10^{\prime \prime}$ \\
\hline Escherichia coli $\ldots \ldots \ldots$ & $>1 \times 10^{*}$ & $>1 \times 10^{s}$ & $>1 \times 10^{\circ}$ & $60 \times 10^{x}$ & $83 \times 10^{\prime}$ & $80 \times 10^{\prime}$ & - & $30 \times 10^{:}$ & $40 \times 10^{7}$ \\
\hline Enterobacter sp. & \multicolumn{3}{|c|}{$>1 \times 10^{8}, 0 I X I<$} & $>1 \times 10^{\circ}$ & $>1 \times 10$ & $>1 \times 10^{\circ}$ & $=1210$ & $80 \times 10^{5}$ & $>1 \times 10^{\prime}$ \\
\hline Proteus mirabilis & $>1 \times 10^{8}$ & $>1 \times 10^{*}$ & $>1 \times: 0^{x}$ & $>1 \times 10^{-}$ & $>1 \times 0^{\prime}$ & $>1 \times 10^{\prime}$ & $>1 \times 10^{\circ}$ & $>1 \times 10^{s}$ & $>1 \times 10^{5}$ \\
\hline
\end{tabular}




\section{QUADRO IV}

Efeío do meio de Rappaport modificado (*) sôbre diferentes espécies de Enterobacteriaceae

\begin{tabular}{|c|c|}
\hline Espécie & Inóculo $(\mathrm{em} 0,1 \mathrm{ml})$ \\
\hline
\end{tabular}

Shigella dysenteriae

Shigella flexneri

Shigella boydii

Shigelle sonnei

Salmonella typhi

Salmonella typhimurium

Escherichia coli

Proteus mirabilis

Enterobacter sp.

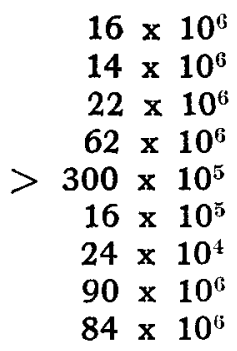

$<1 \times 10^{1}$

$<1 \times 10^{1}$

$<1 \times 10^{1}$

$<1 \times 10^{1}$

$250 \times 10^{5}$

$>1 \times 10^{8}$

$<1 \times 10^{1}$

$>300 \times 10^{5}$

$>1 \times 10^{6}$

(*) Com $1,8 \%$ de $\mathrm{MgCl}_{2}$ e $0,16 \%$ de $\mathrm{NaH}_{2} \mathrm{PO}_{4}$

servaçócs, não podemos dizer que clas se opōem às verificações de autores $(1,4,7$, 8, 9) rio o achiom sumerior a outros meics disponiveis mas sem dúvicia fortificam a impressão ce Eanie (1) de que a concentraräo original do cloréo de magnésio parere texessiva mesmo iara salmonella. No entanto, é de lamentar-se que só essa concentração é que demonstrou inibição suficiente do crescimento de $\boldsymbol{P}$. mirabilis. De fato, parece ser esta espécie a que provoca as maiores dificuldades para o isolamento de Salmonella, em face aos recursos presentemente disponíveis para êsse nropósito (14).

Os fosfatos ácidos de pctássio e de sódio, utilizacos nas mesmas concentraçōes, não justificam que a diminuição do poder

\section{QUADRO V}

Efeito de soluções concentradas de tiosulfato de cálcio e tiosulfato de magnésio sôbre o crescimento de Shigella

\section{Espécie}

Ve células em $0,1 \mathrm{ml}$ de meio após 24 horas a $37^{\circ} \mathrm{C}$ Inónio Sol tiosulfato de $\mathrm{Ca}(*)$ Sol. tiosulfato de $\mathrm{Mg}^{*}$ (*) (em $0,1 \mathrm{~m}$ ! $0,5 \mathrm{ml} \quad 0,7 \mathrm{ml} \quad 0,9 \mathrm{ml} \quad 1,3 \mathrm{ml}$

$\begin{array}{lccccr}\text { Shigella dysenteriae } \ldots & 150 \times 10^{4} & 70 \times 10^{3} & >300 \times 10^{1} & 22 \times 10^{1} & >300 \times 10^{1} \\ \text { Shigella flexneri } \ldots \ldots & >1 \times 10^{4} & 29 \times 10^{3} & 37 \times 10^{3} & 46 \times 10^{3} & 46 \times 10^{2} \\ \text { Shigella boydii } \ldots \ldots & 151 \times 10^{3} & 63 \times 10^{3} & 61 \times 10^{3} & 47 \times 10^{3} & >300 \times 10^{2} \\ \text { Shigella sonnei } \ldots \ldots & 267 \times 10^{3} & 98 \times 10^{4} & >300 \times 10^{3} & 38 \times 10^{4} & >300 \times 10^{2}\end{array}$

(*) Para $5 \mathrm{ml}$ do meio básico. 
inibidor pelo sal de sódio seja devida a uma diminuição da hipertonicidade do meio, pcis, daclo o menor pêso molecular do sódio em relação ao potássio em igualdade de concentração e graus comparáveis de solubilidade, isto não seria justificável.

Como já reconhecido, pelo seu emprêgo $\mathrm{cm}$ outros processos de enriquecimento, a seletividade do veide malaquita para as salmonellas parece confirmada.

\section{summary}

The selective and suppressive mechanism of Rappaport's medium as related to the growth of different species of Enterobacteriaceae was evaluated. With the hyperionic medium, which includes 3.6 per cent magnesium chloride, growth of Salmonella typhimurium was suppressed, this specie being inhibited even with a 3.1 per cent concentration of the same compound in the medium. Suxpression of growth for the otiner species was found at 1.8 per cent moglesinm chioride for the Shigellae, 2,2\% for Escherichia coli, 3,1\% for Interobactar sip., and only when reached $3,6 \%$ for Proteus mirabilis.

ivalachite green, at 0.012 per cent concentration, as in the original medium, was inhibitory for most tested species, with the exciusioit of Entercbacter ant S. typhimur um.

Ely substituting acid sodium phosphate for the original potassium phosphate, a general decrecise of the suppresive characterisitic of the medium occured.

The four Shigella species were most sensitive to the magnesium chloride hyperionic solut ons, among the enteric organisms tested, and similarly they did noi grow in iwo oiher hypertonic media with calcium or magnesium thiosulfate, instead.

\section{BIBLIOGRAFIA}

1. ANDERSON, $\mathbf{K}$. \& KENNEDY, $H$. Comparison of selective media for the isolation of Salmonellae. J. Clin. Pothel., 18: 747-749, 1965.

2. BANIC, S. A new enrichment medium for Salmonellae. J. Hyg., 62: 25-28, 1964 .

3. BRATDE M. A., SUASSUNA, I \&. SUASSUNA, I. R. Inibição do crescimento de Salmonella e Shigella em Agar S. S. Ciênc. \& Cult. 19: 421422,1967 .

4. COLLARD, P. \& UNWIN, M. A trial of Rappaport's medium. J. Clin. Pathol. 11: 426-427. 1958 .

5. COCTA G. A., SCORZELLI Jr., A., SUASSUNA, I. R., SUASSUNA, I. \& GóES, P. de. Comparação de meios seletivo-indicadores e de enriquecimento usades no isolamento de enterobactérias patogênicas. An. Microbiol. 5: 239-304 1957 .

6. FALCAO D. P., SUASSUNA, I. \& SUASSUNA, I. R. Comrontamento de algumas enterobactérias no meio de Ranpano:t, com referência espfcial a 5tiñ. Ciên. \& Cult., 19: 457-458, 1967.

7. HCOPFR, W. L. \& JENKINS, H. R. An evaluation of Rapnapcrt's magnesium chloride/malachite green me- dium in the routine examination of taeces. J. Hvo.6 63: 491-495, 1965.

8. IVESON, J. B. \& KOVACS, N. A comparative trial of Rappaport enrichment medium for the isolation of Salmonellae from faeces. J. Clin. pothal. 20: 200-293. 1967.

9. IVESON, J. B., KOVACS, N. \& LAURIE, W. An improved method of isolating Salmonellae from contaminated diseccated coconut. J. Clin. Pathol., 17: 75-78, 1964.

10. RAJ, $H$. Enrichment medium for selection of Salmonella from fish homogenate. Appl. Microbiol., 14: 12$20,1866$.

11. RAPPAPORT, F. \& KONFORTI, N. Selective enrichment medium for paratynhid bacteria. Appl. Microbiol., 7: 63-66, 1959.

12. RAPPARPORT, F., KONFORTI, N. \& NAVON, B. A new enrichment medium for certain Salmonella. J. Clin. Pethol., 9: 261-266, 1956.

13. RAPPAPORT, F., SKARITON-LOEWENTHAL, M. \& OLITZKI, A. L. A culture medium for the enrichment of Salmonellae and growth inhibition of Proteus. Bull. Res. Counc. Israel, 2: $448-449,1953$. 
14. SUASBUNA, I. Estudos sôbre o gênero Proteus. Tese. Faculdade de Ciências Médicas, Universidade do Estado da Guanabara. Rio de Janeiro. 145 p., 1963 .
15. ZAJC-SATLER, J. \& BANIC, S. Efficacy of different selective media for the isolation of Salmonellae from iaeces. - Clin. Pathol., 18: 750-751, 1965. 